\title{
Chapter 13 \\ Formal Education as a Facilitator \\ of Migration and Integration: A Case Study \\ of Nigerian University Graduates
}

\author{
Melanie Mbah
}

In this chapter I examine the triple nexus of education, migration, and integration. I analyze how formal tertiary education facilitates emigration and integration. My research draws on 65 semi-structured interviews with highly skilled ${ }^{1}$ Nigerian migrants in the three destination countries of Germany, the United Kingdom, and the United States. Furthermore, in combination with data from a web-survey I conducted with Nigerian university graduates from three Nigerian universities, a complex picture emerges illustrating this triple nexus. Educational attainment in Nigeria can be interpreted as taking a person one step closer to the overall aim of migration. Choosing Nigeria as a case study had four main reasons. The country has (a) the biggest population in Africa, (b) a large number of tertiary education institutions with many graduates, (c) high and still-rising numbers of highly skilled migrants, and (d) an important political and economic role in West Africa. Nigeria is intertwined in the West African migration system, both as a receiving and a sending country. A better understanding of Nigerian migration patterns also means more knowledge about West African migration patterns in general.

Taking a cultural perspective on migration, it can be interpreted in the Nigerian setting as something one is expected to achieve as it is a part of the Nigerian culture. More than 20 years ago Tony Fielding (1992) made an important statement that

\footnotetext{
This paper is based on findings of my $\mathrm{PhD}$ thesis, Brain Drain aus Entwicklungsländern? Migrationsmotive und -prozesse Hochqualifizierter am Beispiel von Nigeria. (Brain Drain from Developing Countries? Migration Motivations and Processes of Highly Skilled Nigerian University Graduates), Karlsruhe, 2014.

${ }^{1}$ Highly skilled Nigerian migrants are defined as people with a first university degree who have been living outside their country of origin for at least 1 year.

M. Mbah $(\varangle)$

Institute for Technology Assessment and Systems Analysis (ITAS), Karlsruhe Institute of Technology, Karlsruhe, Germany

e-mail: melanie.mbah@kit.edu
} 
"migration tends to expose one's personality; it expresses one's loyalties and reveals one's values and attachments often previously hidden. It is a statement of an individual's world-view, and is, therefore, an extremely cultural event" (p. 201). Fielding is pointing out that migration is part of a culture, and cultures influence migration processes differently. The role of culture in migration decisions can be viewed in two ways. First, places with strong place-identities produce low out migration and high return migration. Second, conformity with the dominant culture plays a significant role. This means that in places where conformity is high, low migration rates can be identified, and vice versa (Fielding, 1992, pp. 203-204). Furthermore, "how the migration is experienced depends on both the cultural characteristics of the migrant and the cultural context of the migration decision" (Fielding, 1992, p. 205). Cohen and Sirkeci (2011) widen Fielding's approach of cultural migration into cultures of migration. With this, they consider migration as culturally framed and socially defined. For this reason Cohen and Sirkeci (2011, pp. 10-19) argue that migrants usually have a plan beforehand; migration, therefore, is strategically planned and the migration process itself underlies a subjective rationality based on expectations of positive outcomes. Migrants are, of course, social actors "framed by traditional beliefs, cultural expectations, and social practices" (Cohen \& Sirkeci, 2011, p. 14) and the sociospatial setting plays a crucial role as well. They conclude that:

individuals have nearly limitless needs and wants but only limited means through which to satisfy them. In this situation migration becomes an important avenue toward satisfying those wants - not all of them, but certainly more than might be possible without migration. (p. 19)

Drawing on this latter point, I argue that formal education is one of the facilitating means for migration. Education is highly valued in Nigeria because it is understood as a means of satisfying people's needs and wants. It is often unable to fulfil those expectations and ends up having the effect of creating another desire: the one for migration, which many consider an answer to their needs.

Within the nexus of education, migration, and integration, I (a) highlight the Nigerian migration history to integrate it into a cultural perspective of migration; (b) focus on emigration patterns of highly skilled Nigerian migrants to understand better their motivations and how migration is actually realized; (c) explain integration as a complex process dependent on structural forces and individual abilities; and (d) introduce a new migration model for West Africa that reflects the migrant's point of view. I argue that migration is a continuum in space and time leading to several outcomes that can be explained with the concepts of brain drain, brain waste, and brain circulation.

\section{Methodology and Data}

The findings are based on my analysis of: (a) 65 semi-structured interviews I conducted with highly skilled Nigerian migrants in Germany, the United Kingdom, and the United States in 2011 and 2012, and (b) a web-survey of alumni from 
three Nigerian universities (Ibadan, Jos, and Port Harcourt) I carried out in 2010-2011.

My analysis of the web-survey of 244 participants (from a database of 2874 alumni) provided detailed information about the interviewees' educational and socioeconomic backgrounds and other matters such as their occupational careers and international experience. The gender distribution of the participants was $70 \%$ male and $30 \%$ female. A majority of participants were between 26 and 45 years old and about $60 \%$ of them were married and had family. About $10 \%$ of the participants had international experience, either in the form of study leaves or work experience.

The age distribution of the interviewees in the semi-structured interviews ranged from 25 to 64 years, with most being between 30 and 50 years old. I interviewed 25 women and 40 men. The minimum amount of time spent in the destination country at the time of the interviews was 1 year and the maximum was 31 years.

All of the interviews were conducted face-to-face, except for one telephone interview. The interviews were recorded and transcribed completely, to miss no important detail. The length of the interviews ranged from $30 \mathrm{~min}$ to $2 \mathrm{~h}$. This variation in length depended on where they were conducted, whether in public (e.g., cafés or work places) or in private spaces (e.g., homes or cars). This also greatly influenced the atmosphere of the interview. Of course, interviewer effects had to be considered and were avoided as much as possible.

The analysis of the interview transcriptions was made in two main steps. First, sections of the transcriptions were categorized in codings to obtain a proper picture of the central issues mentioned. Second, a variety of types were identified and verified several times regarding their inner cohesion and outer distinction. The six types identified were then entered into a time-space continuum, which served as the basis of an actor-centered migration model representing the migrants' perspective on the migration process. This approach helped to reveal which structural opportunities and constraints migrants face when trying to integrate themselves into the host societies. Quotations as well as narrations of migrants' biographies are used in the following sections to gain a better understanding of the migrants' point of view. Anonymity is guaranteed by the usage of pseudonyms for all interviewee names.

\section{Nigerian Migration History: Migration as a Cultural Event?}

The cultural perspective can be projected onto Nigerian migration patterns because of Nigeria's extensive migration history, including immigration and internal migration, as well as emigration. In many ways, Nigeria is typical of West African migration patterns; after its independence from the United Kingdom in 1960, it initially suffered an exodus of the highly skilled, induced by both British and Nigerian politics. As a British colony the country inherited the British educational system. Efforts to achieve development through education in the early years of independence produced many secondary school graduates who could neither be absorbed by the 
Nigerian economy nor find space in tertiary education institutions. Therefore, many Nigerians and nationals of other West African countries chose to migrate to the former colonial powers or to the United States. National policy also fostered these migration streams, with the former colonial powers often having liberal visa programs, and the Nigerian government implementing several educational programs to educate Nigerians abroad (Adepoju, 1985, 1995; Makinwa-Adebusoye, 1992). Those former developments are still affecting today's migration patterns, with the United Kingdom, for example, being the first migration choice for Nigerians if their migration is educationally driven. During colonial times British rule created highly mobile populations. In addition to the widespread rural-urban and north-south movements in response to climate conditions and economic differences, a second and opposite south-north stream, comprised mainly of Igbo $^{2}$ people, emerged because of an educational south-north gradient and the need for educated administrative staff in the north (Swindell, 1995). The artificial separation of members belonging to the same ethnic group as a result of the border demarcation fostered undocumented migration between neighboring countries, a problem that persists to this day (Makinwa-Adebusoye, 1992). Another important cause was the Biafran War between 1967 and 1970, which induced internal as well as international migration streams (Falola, 1999; Swindell, 1995).

Migration, both domestic and international, is thus a longstanding part of Nigerian culture. It developed from internal, nomadic movements into rural-urban mobilities and continues with international migration driven primarily by economic and educational considerations to other (West) African countries and destinations abroad (mainly the United Kingdom and the United States). Nowadays there are many different forms of movements, ranging from emigration to back-and-forth moves, remigration, and re-emigration. In the case of the Cape Verde Islands, Carling and Akesson (2009, pp. 123, 132-140) attested a migration ideology shaped through large-scale labor emigration flows between the 1960s and 1970s. Migration is now a part of Cape Verdeans' everyday lives because it has such a pervasive influence in their society, with many Cape Verdeans receiving phone calls and remittances from migrants abroad, as well as experiencing houses being built by migrants. This migration ideology, or migration culture, applies in other cases as well, such as Nigeria or, for instance, Uganda (e.g., Binaisa, 2009), Ghana (e.g., Nieswand, 2014; Smith, 2015), Mexico (e.g., Goldring, 2001), or Asian countries such as Bangladesh (e.g., Dannecker, 2009), Indonesia, and China (e.g., Xiang \& Lindquist, 2014). Additional to this migration culture, push and pull factors may have a formative influence on images migrants have of countries abroad. Those push and pull factors refer to the political, economic, and educational situation in the countries of origin and destination that can lead to an image of "greener pastures" abroad.

\footnotetext{
${ }^{2}$ Nigeria has more than 250 ethnicities. The Igbo is one of the three main ethnic groups (Hausa, Igbo, and Yoruba).
} 


\section{Emigration as Culturally Underpinned and Realized Through Education}

My understanding of emigration as being culturally underpinned means that my research is located within the cultural optic of migration research (Cohen \& Sirkeci, 2011; Fielding, 1992). The notion of culture is, therefore, shaping migration aspirations (Carling, 2014; Carling et al., 2013; Efionayi \& Piguet, 2011). I also draw on concepts focusing on networks as being crucial to migration decisions (Choldin, 1999; Fawcett, 1989; Kennedy \& Roudometof, 2002; Larsen, Urry, \& Axhausen, 2006; Mitchell, 2000; Tilly, 2007). Carling (2002) identified involuntary immobility as one important pattern of today's migration. He argues for a separate analysis of the aspiration and the ability to migrate and introduced an aspiration-ability model. In my case study, the ability to migrate has already been proved, but what facilitated the ability to migrate can be clarified. It remains to be analyzed whether the aspirations can be interpreted as cultural in the sense of imaginaries leading to the migration aspirations of societies and how aspirations come into existence. Carling (2014) acknowledges that desires for migration are "a fundamental aspect of society that affects its life and development" (p. 5). He therefore proposes a new model of migration decisions. Migration aspirations comprise both the desire and the capability (or lack thereof) to move, which may result in mobility or immobility. If the goal has not been achieved or the opposite of what has been wanted is realized, Carling speaks of repression rather than realization (Carling, 2014). This same concept supports the development of my migration model. While Mitchell (2000) and others argue for networks as the most important variable fostering migration decisions, I argue that the media and narratives of migrants and return-migrants have developed a special image of greener pastures abroad and continue to nourish it. This myth leads to such an overwhelming desire for migration that contradictory information is not adequately considered in the process of migration decisions.

Considering that a migration desire without migration ability cannot lead to a migration decision, there is a need to examine other determinants. Some important facilitators of migration are, among others, access to networks (kin or business) and formal education (Castells, 2000; Choldin, 1999; Hardwick, 2008; King, 2012; Larsen et al., 2006; Mitchell, 2000; Tilly, 2007). Moreover, my findings show that visa requirements, in particular, can be very challenging to most seeking to leave a country, confirming the influence of structural factors. A closer look at the literature on decision-making processes of migrants shows that they are quite complex, and that the models explaining them tend to be abstract (Cebula, 1979; DaVanzo, 1981; Gardner, 1981; Parnwell, 1993; Wolpert, 1965). Goldin, Cameron, and Balarajan (2009, pp. 97-120) identified three levels of decision-making, namely the individual, the societal, and the national influences. These levels attest to the complexity of migration decisions and the importance of not overemphasizing any single one in particular. Hence, I argue for a complexity of migration decisions in which images and imagination play a crucial role, as do other factors such as networks and economic, political, or educational circumstances. Literature focusing on networks as 
part of a newer explanatory concept in migration studies argues that networks are social ties determining the individual's opportunities to act (Hardwick, 2008; Mitchell, 2000). Networks, therefore, foster migration decisions, because they make migration processes less risky and costly, thus generating chain migration (Portes \& DeWind, 2004). My contribution in this chapter to the issue of networks is to view them from a different perspective, less as decision-makers and more as facilitators to implement a decision already made. Therefore, both education and networks are important facilitators of migration.

Why do I come to this conclusion? In my analysis of the web-survey I observed a multifaceted picture of migration aspirations and facilitators. Large family networks work as a push factor for migration in that they may be an asset in terms of financial, social capital, or accommodation issues, both in Nigeria and abroad, that eases educational attainment and migration. Furthermore, large families may depend on migration to generate higher household income to satisfy their own needs in their country of origin. Education facilitates migration because it is easier to access migration channels with a university degree. First, a graduate with a first degree seems to have a better chance of obtaining a student visa to study abroad. Second, students at universities gain access to diverse networks and groups, as well as to ideas and knowledge, which may motivate them more to go abroad to study. Third, those who choose a career in science need to acquire international experience to be competitive in the job market. A majority (76\%) of those alumni already living abroad when the web-survey was conducted (2010-2011) stated that educational attainment was their main motivation. This was also true for alumni who lived in Nigeria but had international experience. A minority had been abroad for holidays and very few of those who had spent time outside of Nigeria indicated having international work experience. Educational attainment abroad, therefore, has added importance for Nigerian migrants and former migrants.

Taking the standpoint that migration is a cultural matter, the findings of my study show that a rather naïve image of life abroad quite often leads to migration decisions. Migrants often follow the routes of former migrants. Prospective migrants are, therefore, more concerned with the question of how to enter the migration process than what kind of outcome migration will have or how to influence the outcome. Accordingly, Nigerian migration history has induced a culture of migration expressed in the belief that abroad is paradisiacal. Narratives of highly skilled Nigerian migrants indicate that images are created not only through migrants, but through the media as well. John, who had been living in Germany for over 15 years, underlined the importance of media, in combination with narratives of migrants, in influencing the images generated and the aspirations to leave the country:

[Y]ou see all the beautiful things...in movies,... and they tell you yes it's basically the thing you see on the movie and life is good, everything is wonderful here and the rest of it. Of course, you want to be part of it.

This one-sided image of destination countries is accompanied by an expectation of going to the United Kingdom for studies and returning to be immediately absorbed into the Nigerian labor market. Susan, for example, who had been living 
in the United Kingdom for 3 years at the time of the interview, came to study and had recently finished her master's degree. She had experienced people who had left Nigeria for further education and returned to Nigeria being more competitive than Nigerians who have not been abroad:

Actually the idea of studying abroad...came from my previous background because I did have my internship with Chevron Nigeria Limited...I found that some of my bosses actually studied abroad and then they came back to Nigeria to work.

The examples above reflect the image of the country of origin "as underdeveloped space" (Akesson \& Baaz Eriksson, 2015, p. 23) and the migrants as being "more developed and advanced" (p. 23) after acquiring western university education and having been migrants in a developed country. The positive image of abroad is so deeply rooted that even strong foundations of trust may not convince prospective migrants of the opposite. This is shown by the statement of Dennis, whose parents had lived in the United Kingdom previously, and who, himself, has been living in the United Kingdom for more than 10 years:

\footnotetext{
You believe that life is better here [in the United Kingdom]. You believe that you can earn a better living here.... My parents were here in [the] seventies but you don't want to believe [them: his parents] because what you see on TV, you watch CNN, you watch movies, and with those the picture that is painted is wonderful, better than what you have in Neija at that point in time...so I was more likely to believe my peers, my friends who had traveled but they never gave us the true picture but even if they did, we would still have some doubts as in then "why are you there, why haven't you run back?"
}

The image of greener pastures is fed and preserved by migrants who feel forced to appear to be successful people, even if they are not. The role of one who has made it is also attractive to the migrants because of the accompanying gain in status. The following quote from Michael, who was living in the United States, describes this very vividly:

In Nigeria everybody, if you come from here [the United States], everybody is like "ooh"! They respect you, they fear you, they follow you around [and] you feel big!....Everybody wants to stay in line and talk to me...so we, that are there [before emigration], we thought it is going for him, if I can go over there it will go for me.

Fostering the migration decision is the image of greener pastures, a perception that generates aspirations and desires for migration and spawns a culture of migration in which the question becomes how to leave the country rather than if or why to leave the country. As George, who had been living in Germany for more than 19 years, put it: "If you can leave, you know just leave,...God will be with you."

Migrants search for facilitators to aid their entry into the migration process, but do not examine, for instance, what a foreign system really looks like and how they will adjust to it. The question raised in this section is: How do highly skilled Nigerian migrants carry out their migration decision? Which factors - facilitators as well as constraints - can be identified?

The threshold approach of van der Velde and van Naerssen (2015) focuses on all dimensions of the decision-making process at the personal and structural levels, including those "affecting whether, when and where to migrate" (p. 6). In their 
approach, the personal level also comprises social networks and the level of information available. The structural level considers the socioeconomic and political situation. They identified three thresholds: the mental threshold (the mindset of people to become a migrant), the locational threshold (familiarity with the destination country), and the trajectory threshold (route to the destination country) (van der Velde \& van Naerssen, 2015). My findings support this thresholds approach on three accounts. First, the mental threshold is regarded as the imagination leading to the aspiration for migration. Second, the locational threshold comes into play through the role of networks. My findings indicate that networks do play a role when potential migrants are actively looking for possibilities to leave the country and are big facilitators in the realization of that dream. Third, the trajectory threshold takes into account the possibility that certain factors in a particular migrant's life may outweigh other trajectories; for example, if a certain individual is less able to connect to networks than another. The most important facilitator for highly skilled Nigerian migrants in this regard is university education, because it allows them to apply for a student visa, which seems easier to obtain than other types of visas. Some students in the United Kingdom told me, for example, that they had planned their migration for a long time and even saved money to pay the university fees in the United Kingdom. Nonetheless, not everyone who faces difficulties in the country of origin or simply aspires to migrate has the resources and capability to do so. Other factors such as networks and sociospatial contexts play a role in having access to migration. In this regard Smith's (2015) description of a Ghanaian prospective migrant who migrated to the Netherlands indicates that networks, as well as coincidence, play a crucial role. That particular migrant had an uncle, a man of influence with a huge network, who helped him obtain a visa and financed his flight. Such "big men" are gatekeepers to resources and networks (e.g., Utas, 2012). There might be a hidden rationality behind the myth of greener pastures that is created mainly through images. The existence of migration facilitators, such as education, dual citizenship, green card or marriage offers, and financial assets, strengthen the idea of migration as a relevant solution.

\section{Integration Between Structural Forces and Individual Abilities: Migration as a Continuum in Space and Time}

The above argument of a culture of migration now leads to the following question: How does the aspiration of highly skilled Nigerians to migrate affect the Nigerian educational system? With this inquiry I aim to challenge the rather negative perspective on brain drain, taking into account more positive interpretations of brain circulation. I argue - in spite of a certain extent of brain drain - for a type of brain circulation that could be supported through specific policy programs and progress in the quality of education in Nigeria itself. Most graduates leave the country after completion of a bachelor's degree in order to gain an international degree (master's 
or $\mathrm{PhD}$ ). This rather low level of tertiary education on the part of migrants can therefore not really be interpreted as brain drain. The focus should lie on the question of what happens to those who emigrated to further their education abroad with the intention of returning after graduation. The findings show that most highly skilled Nigerian migrants face difficulties furthering their education abroad, starting with the issue of getting their degrees accredited by the host country's educational system. This accreditation process requires either re-examination, which takes time and can be quite expensive as well, or starting over, which means repeating their university education from scratch. Neither of these possibilities is attractive from a migrant's point of view. The quantitative data provides some evidence of the extent to which Nigerian graduates are involved in migration and what motivations they have. As stated above, $10 \%$ of the alumni ${ }^{3}$ migrated, but the data also covers return migrants and non-migrants on short-term stays abroad.

The analysis of the qualitative data revealed a typology of the highly skilled Nigerian migrants that may be linked to certain knowledge flows, namely brain waste, brain drain, and brain gain or brain circulation (e.g., Salt \& Findlay, 1989; Chikanda, 2007; Lee \& Kim, 2010; Pecoraro, 2013). Out of the 65 interviews, six types of migrants were identified: student migrants, privileged migrants, establisher migrants, dependent migrants, integrated migrants, and transmigrants. Student migrants typically are in the country of destination for a few years (1-5 years), are actively involved in education, send no remittances (indeed they are likely to be receiving remittances from Nigeria), and are willing to return after graduation, or after some work experience, if conditions in the home country are right. Privileged migrants are involved in different fields, including education, but may also be employed. For them migration is easier to access because they already possess a residency permit for the country of destination through their familiar relations. That advantage, as well as their larger and often more well-established networks, gives them better access to the labor market in the destination countries. Moreover, those traveling to the United Kingdom whose parents are return migrants have better language skills, another benefit for labor market integration. They send no or only small amounts of money to their country of origin, either because most of their family members are abroad or because their family members in Nigeria are well off and they do not actively plan their return. Their length of stay in the country of destination varies, with some of them, therefore, visiting Nigeria only periodically, which means less than every 3 years. The third type, the establisher migrant, is struggling to integrate into the host society, mainly doing menial jobs, trying to succeed, but facing various setbacks or failures. Establishers have responsibilities in both societies (Nigeria and the host country). They send remittances to Nigeria, although they have to take care of family members in the country of destination as well. They do not plan to return because they do not have the means to do so. Dependent migrants are those highly skilled Nigerian migrants who did not decide on their own to migrate; rather they married a Nigerian who already lived in the country of

\footnotetext{
${ }^{3}$ Alumni are here Nigerians who hold a university degree (first or more) from one of the three Nigerian universities (Ibadan, Jos, Port Harcourt).
} 
destination. Their everyday lives are often centered around the family, and they may have children born shortly after immigration or even prior to it. The fifth type is the integrated migrant. They are well integrated into the host society, meaning they have well-paid jobs in the tertiary or quaternary sector. They have family in both societies and thus responsibilities to take care of in both countries, including sending remittances. Integrated migrants make visits to Nigeria either regularly (once a year) or periodically (less than every 3 years). Whether they will return permanently to Nigeria in the future is unclear because they feel at home in both countries. The last type of migrant is the transmigrant. These migrants are highly mobile, with travel being their most important characteristic. Visits to Nigeria are made not only regularly, but in fact quite frequently, meaning more than once a year. Keeping in contact with people in both countries is part of this type of migrant's everyday life because they are often involved in typical migrant entrepreneurship. They also face responsibilities in both societies but find it easier to fulfill them because of their close contacts with people in both the destination and source countries. The status of transmigration means having fulfilled the aim of being part of both cultures without losing one's sense of identity or home.

Based on these types, I argue for a conceptualization of migration as a dynamic process with several possible trajectories, depending on the individual's development and preferences, which evolve over time and space. The types, too, therefore must be regarded as non-static affiliations that change along with a migrant's experiences, preferences, and choices. For a better understanding, I base my argumentation on the example of a biography of a migrant, James, who migrated to the United Kingdom in 2004 (Fig. 13.1), 2 years after completing his first degree in Nigeria. He was born in the United Kingdom and lived part of his childhood there. His parents returned to Nigeria when he was in his first year of secondary school, in 1989, when he was 12 years old. His migration was first as a dependent type and then as a privileged type. I mention the former type from the first phase of the life cycle and his early childhood, in spite of that period not having been part of an independent migration process, because it did influence his migration biography. Both of his parents had studied in the United Kingdom but then decided to return to Nigeria: first just his father, who worked in Nigeria as a banker, and later the whole family. James recounted that it had always been clear to him that he would re-emigrate to the United Kingdom one day. After finishing his bachelor's degree, he did his National Youth Service Corps in Nigeria with Chevron, an experience that reinforced his wish to emigrate to the United Kingdom all the more. Although he was privileged in the sense that he already had British citizenship and relatives in the United Kingdom who backed him financially, he struggled finding a job. It took him 1 year to find a job, but he finally found work as a "custody officer" (his own term). He went on to finish his master's degree with the hope of finding a better job in the United Kingdom, although he had in the meantime managed to acquire property for himself and his nuclear family (showing that he was becoming an integrated type). He continued to communicate with people in Nigeria, visited Nigeria on a regular basis, and established a migrant entrepreneurship initiative (as he attempted to develop into a transmigrant). His parents and some of his siblings were in Nigeria; 


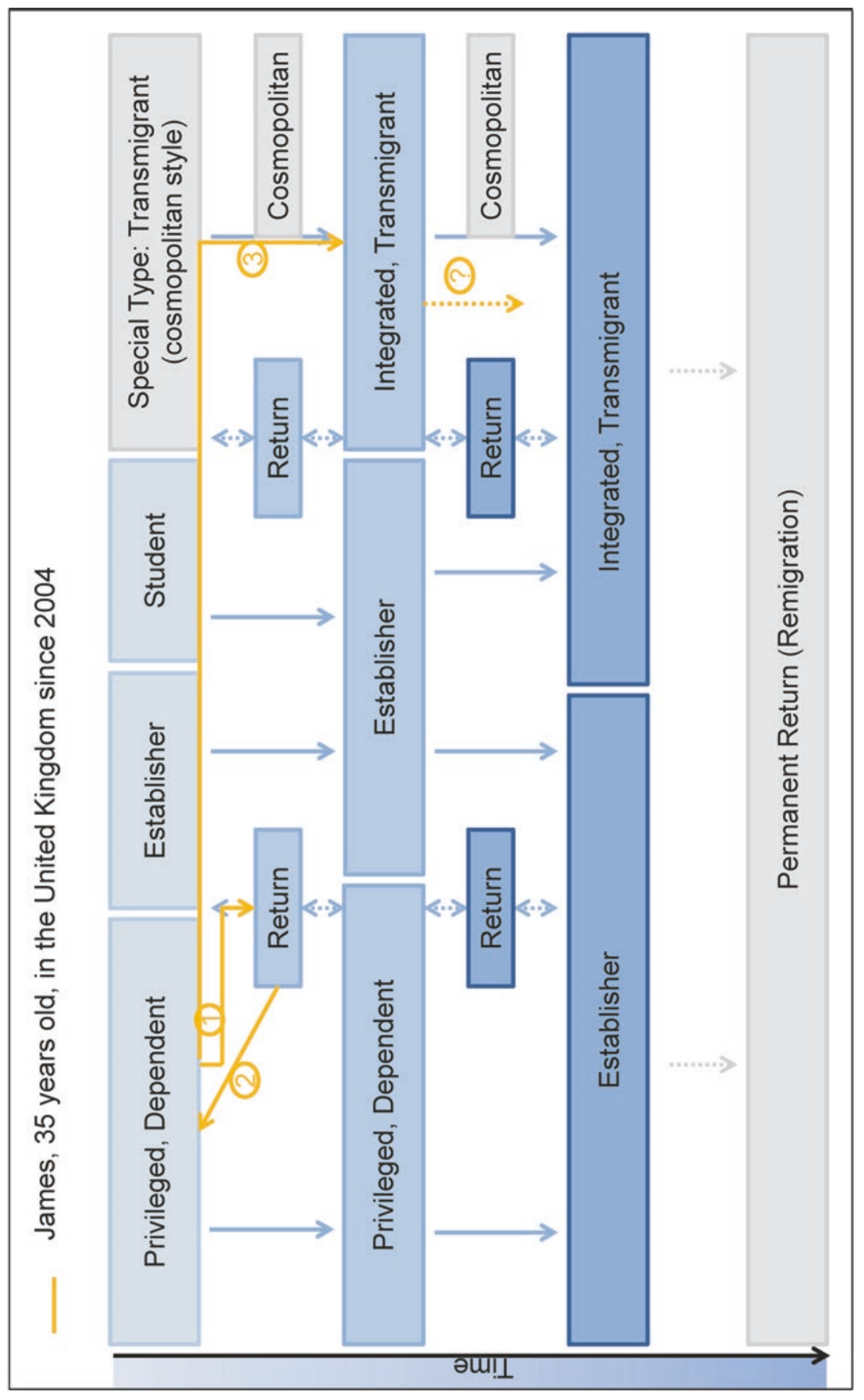

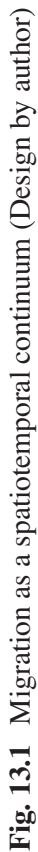


his brother and other relatives were in the United Kingdom, as were his nuclear family of his wife and two children. He did not know if and when he wanted to return, because it was initially important to him to let his children grow up in the United Kingdom so that they would receive a Western standard of education. According to this narrative, it appeared that he would either continue to tend toward being the integrated type or would become a transmigrant in the future.

In summary, the proposed model of a spatiotemporal migration continuum shows (a) that individuals develop over time and can therefore change from one type of migrant to another. There are four classic initial types: the student, the privileged, the establisher, and the dependent migrant. Three of these types do not appear to endure throughout the entire migration biography, namely the student, privileged, and dependent migrant types, because individuals join the labor market after residing for differing periods of time in the destination country, depending on the sociospatial context.

(b) Return is not necessarily permanent, but can involve short-term stays as well as periodic visits, with re-emigration after some time becoming a consideration. (c) Migration can involve several countries: at least two, the source and the destination country. (d) Migration can start and continue at various points in life, for instance, as a child, as a student, during work life, and as a retiree. And (e) decision-making during the migration process depends on the current life-cycle phase of the migrant and is influenced by temporal and various sociospatial contexts, as well as by personal preferences, that can either be seen as factors of opportunity or of constraint.

Furthermore, I argue that the six types have different developmental effects with respect to the level of transnationalism and a person's self-identity. Transnationalism is performed in various ways through, for example, visits, communication (phone, email, etc.), and money transfers. The self-identity and emotional belonging regarding where home is depends very much on two factors: first, time spent in the host society, and second, integration into the host society. Migrants can have hybrid identities and regard more than one place as home (see also Ralph \& Staeheli, 2011). Referring to my argumentation regarding the six types, it is possible (following Faist, 2008) to categorize those types according to three possible knowledge flows (brain drain, brain waste, and brain gain or circulation) that are taken as synonyms for development pathways (Fig. 13.2).

Brain drain stands for a loss of knowledge from the source country's perspective. This applies to migrants who are highly skilled (holding a bachelor's, master's or higher degree) and emigrate-perhaps after collecting some work experience-to another country, losing every link of exchange with the country of origin. The knowledge these migrants acquired in the country of origin now contributes to the development and competitiveness of the country of destination. This is particularly true because highly skilled migrants are regarded as human capital, a fact that helps 


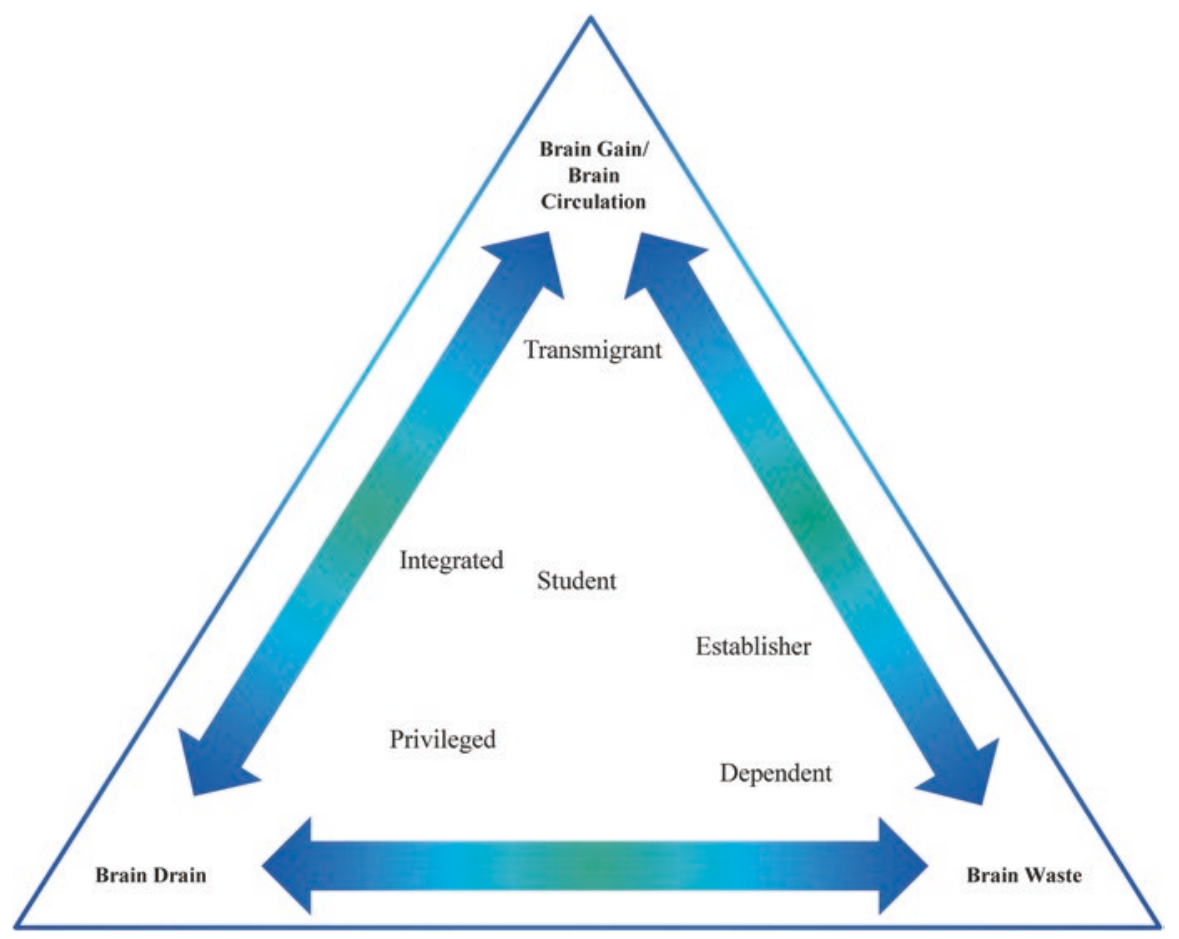

Fig. 13.2 Developmental impacts of migrants in reference to different knowledge flows (Design by author)

them integrate into the labor market of the host society and also guarantees the successful utilization of their acquired skills (see also Chikanda, 2007; Rizzica, 2008).

Brain waste is more than just a loss of knowledge, because acquired skills and knowledge remain completely unused in the country of origin, as well as in the country of destination. Brain waste thus means a deskilling of the migrant labor force in host societies (Faist, 2008; Fossland, 2013; Pecoraro, 2013).

In contrast to these knowledge flows that are rather negative from the source country's perspective, brain gain and brain circulation are represented as win-winwin situations. The host country gains human capital, both the home and host society economies experience a positive impact resulting from circulatory knowledge flows, and the migrants themselves also benefit (Salt \& Findlay, 1989; Findlay, 
1995; Jöns, 2009; Lee \& Kim, 2010). The country of destination may also see increased tax income. Remittances to the country of origin supplement its national income. They might also induce development by encouraging higher educational attendance rates and the establishment of small-scale businesses, with new ideas arising from entrepreneurship possibly creating new jobs and income and encouraging a specific societal culture. The migrant benefits from circulatory migration processes in that he or she gains in status, maintains contacts in both countries, develops a hybrid identity, may own two or more homes, and comes to regard transnational activities as self-fulfillment. Transnationalism includes or, at least, promotes brain circulation, which is a process that can support economic development in source countries as Ho (2011), Jöns, Mavroudi, and Heffernan (2015), Larner (2007) and Saxenian (2006) have argued. Some of the migrant types identified here, for instance, the transmigrant, the integrated migrant, and the student migrant, can be located in the spectrum of brain gain or brain circulation. In Fig. 13.2 other migrant types are located closer to the angles marking negatively connoted knowledge flows such as brain drain (the privileged migrant type) or brain waste (the dependent and establisher migrant types).

Simplistic definitions and understandings of knowledge flows are highly contested because migration is viewed as rather multidirectional and complex. Simple contiguities are negotiable and are not suitable for depicting and explaining the nexus between migration and development. Akesson and Baaz Eriksson (2015) argue that policies focusing on brain drain neglect issues of racism and discrimination in the countries of destination that often lead to a downgrading of skills of African migrants. The authors postulate that migrants are also unable to easily transfer skills and knowledge acquired in countries of destination back to their countries of origin to contribute to development there. They see a failure of a bottom-up concept in both cases and a need for a change in policies. In considering Akesson and Baaz Eriksson's (2015) argumentation, I surmise that highly skilled Nigerian migrants do face racism and discrimination, which often lead to a downgrading of skills, but in contrast to the authors' view, I argue that this process of downgrading does not mean that migrants inevitably remain in miserable economic or social situations. Depending on the time spent in the host society, on their sociospatial context and individual capacities, highly skilled migrants are able to get good employment and develop a professional career, as well as contribute to the economic and social development of the origin society.

Moreover, I argue that a focus on economic benefits that can be described as short-term effects is not suitable for evaluating knowledge flows involving highly skilled Nigerian migrants. Instead, social and cultural capital must also be included in the concepts of brain drain, brain waste, and brain gain or brain circulation. As Binaisa (2009), and more specifically Levitt (1998, p. 933), defines social remittances as "normative structures, systems of practice and social capital", I argue that these social remittances have to be included in concepts of knowledge flows. 
I define those developmental effects not only as economic, but also in terms of cultural and social capital. This means that long-term processes, for example, changes of cultural meanings and societal behaviors resulting from new information, and the influence of different ways of life introduced by returning migrants (long and shortterm returns), play a crucial role in such knowledge flows but are not well quantifiable. Jöns (2009) has shown this effect in the context of transnational knowledge networks through the example of circular academic mobility to Germany.

The six types in my typology of highly skilled Nigerian migrants can be sorted into a dynamic system of knowledge flows, as I have illustrated in Fig. 13.2. In that diagram the closer a particular type is to an angle of the triangle, the closer its association with the corresponding knowledge flow is considered to be. Individuals of the types located further away from the angles of the triangle cannot be regarded as expressing one specific knowledge flow. This affiliation may remain so until those individuals change their trajectory as part of dynamic migration processes. Migrants are part of migration processes as long as they continue to move, both in terms of crossing borders and in terms of changing their migrant type. The direction and level of development flows may change over time, depending on how individuals' actions and preferences change.

In this section, I emphasized the dynamic quality of migration processes and linked that aspect to knowledge flows impacting both source and destination countries. A migrant's individual level of development was also considered. Accordingly, migration can proceed along a spatiotemporal continuum, with several potential outcomes contingent on the trajectories taken by individual migrants. These outcomes are not static and evolve in response to the migrants' ongoing development. I was able to classify these into six types of highly skilled migrants on the basis of a case study involving Nigerian university graduates.

\section{Migration Culturally Underpinned and Educationally Materialized: A Migration Model of Highly Skilled Nigerians}

The migration processes described above can be summarized in a migration model presenting the migrant's perspective. I retain an actor-oriented view outlining the structural and individual opportunities and constraints that migrants face. The case study of Nigerian university graduates thus enables a broader understanding of migration processes. The migration trajectory model informed by the migrant's perspective (see Fig. 13.3) describes how the migration process is experienced by highly skilled Nigerian migrants. It takes into account the entire process of migration, describing the reasons for emigration, the decision-making, and actual migration; the aims and hopes of the migrant; and the opportunities and constraints they meet while in the integration process. The model also accounts for a shift of aims that can result from the situational context in the country of destination, from the 


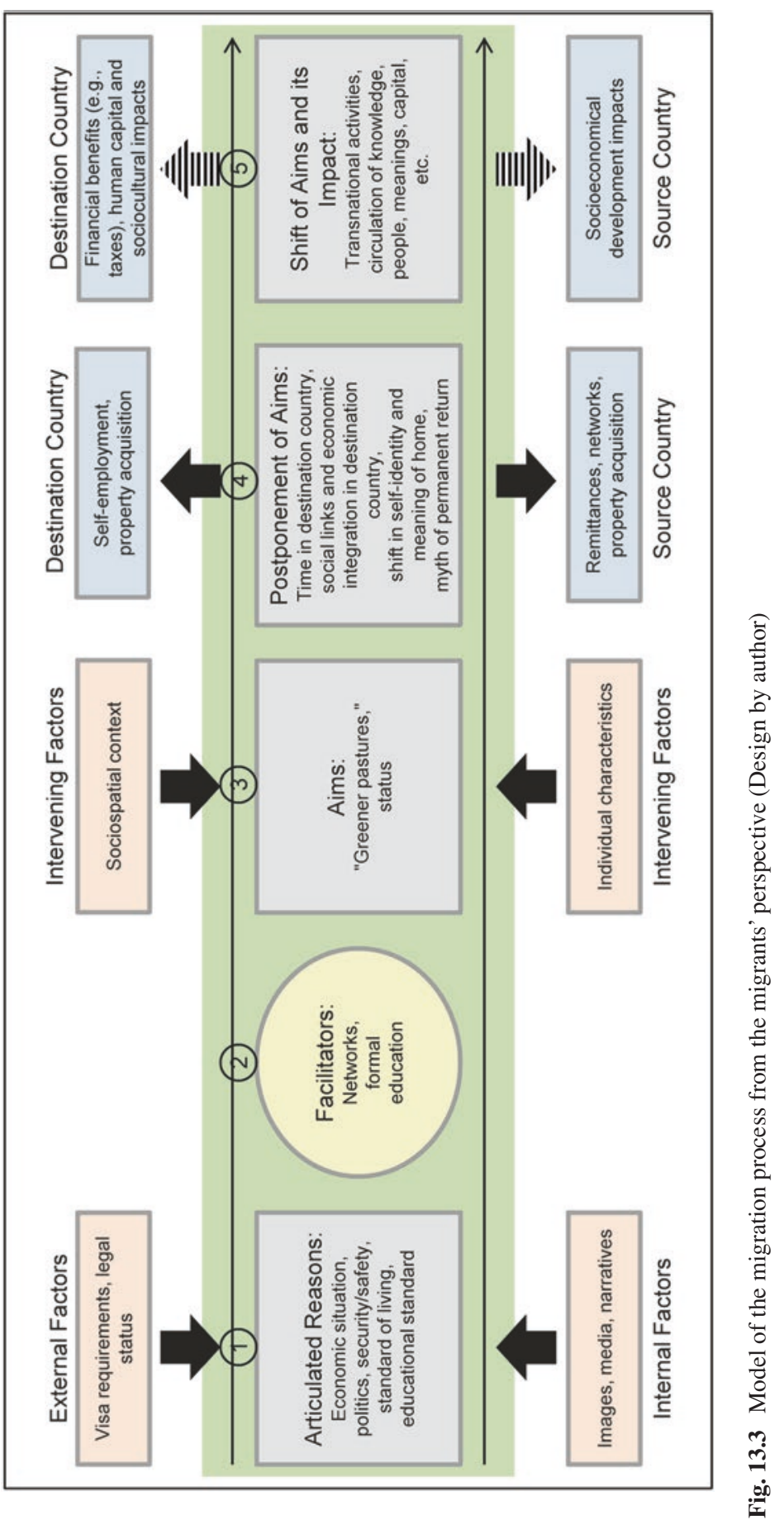


migrants' own change of self-identity, and their altered perceptions of home. The decision-making and integration process is influenced by several factors. These are shown in the boxes with arrows pointing in the direction of the migrants' development status (boxes in the middle lateral segment of the diagram), to be read from left to right. The other boxes indicate migrants' strategies and possible influences on both the country of destination and of origin (arrows indicate the direction of activity).

To describe the model step by step, I start with (1) the reasons articulated for the desire to migrate that are influenced by external and internal factors. External factors come into play through laws and administrative requirements, as well as through special programs undertaken by potential destination countries. These circumstances either facilitate or constrain migration and play a role in the migrant's decision to consider migration. Internal factors are ones in the sending country that may affect the desire for migration through influences such as narratives, media, culture, and specific images. Potential migrants articulated to me various reasons why they considered leaving to be the only or best option, also explaining how they had formulated the wish to migrate and finally actively begun to plan how to accomplish it. From an actor's point of view, these steps may not be occurring sequentially, but simultaneously, and must, therefore, not necessarily constitute a deliberate process. However, my argument is that migration decision making is not that spontaneous in most cases. Rather, it is an underlying wish that is sharpened through several events and influences, and either pushed forward actively or undertaken by chance.

(2) Entering the migration process usually requires some preparation. For highly skilled Nigerians, this includes activating existing networks or developing new ones and meeting visa requirements on the basis of their formal education, an approach that requires opting for a student visa. This is step two in the migration model.

(3) The third step is migration, with certain of the migrants' motivations stemming from the "greener pastures syndrome" and their hopes for higher status in their country of origin.

(4) Migrants pursue those aims according to their individual capabilities, which are quite constrained by their individual characters and their sociospatial contexts in the destination country. Constraints not considered during the migration decision-making process can cause migrants to postpone continually the fulfillment of their previous aims. This occurs mainly because migrants do not adequately inform themselves about the process of integration in the destination country before emigrating. Prior to emigration the question of how to access the migration process is at the forefront, not how to integrate or manage after arriving in the destination country. Migrants, therefore, are forced to postpone their aims in the fourth step, as they realize that they need more time for integration, hence developing other wishes as well as other demands. During the migrants' time of stay in the country of destination, they may be able to develop social links and networks. Social and economic integration is a strategy as well as an aim that causes a shift in the individual's self-identity and understanding of home. The desire for a permanent return to the source country may be continually articulated but postponement and unplanned, yet fostered, integration in the host society (see also Sinatti, 2011) often results in this goal being more of a myth than a reality. Both pathways - return and integration - are maintained in furthering self-employment possibilities related to 
typical migrant entrepreneurship in the country of destination. These enterprises enable migrants to stay linked to both societies and to acquire property in both countries. Remittances are also a manifestation of the promise of return and part of dealing with a migrant's responsibilities in the source country.

(5) Finally, migrants adjust their aims and shift to a transnational way of lifeanother of the potential outcomes of the migration process. Transnationalism includes return migration; whether it is permanent or short term does not matter, because the very strong networks these migrants meanwhile have in both countries have led to significant changes in their self-identities. Migrants now perceive home to be in both places and are eager to keep in touch with their contacts in the source and destination countries. Migrants usually perceive transnationalism as being preferable to permanent return because of their responsibilities and strong links visà-vis the host society and because of their changed, more "hybrid" self-identities and understanding of home. Recent literature (e.g., Akesson and Baaz Eriksson, 2015) takes this preference into account and confirms the interpretation of migration leading to transnationalism rather than permanent return or just integration, with no linkages preserved to the country of origin. With time, migrants appear to be more likely to stay in the destination country, while maintaining strong links to the source country. The destination country experiences financial benefits from this, for instance, in tax income, as well as in the form of the human capital represented by highly skilled migrants who successfully integrate into the labor market and make use of their acquired knowledge. Furthermore, migrants may have the sociocultural impact of creating a multinational society with different cultures, languages, and mixtures of those. The source country may also experience socioeconomic change, as the narratives of migrants continually shift images and cultures; temporary return visits lead to exchanges between migrants and non-migrants, possibly fostering knowledge transfers, remittances, and even income generation and entrepreneurship in the source country.

\section{Conclusions}

In this chapter, I have suggested considering education not only as a driving force of migration undertaken to acquire knowledge but also as an instrument for gaining access to migration processes. Applying a cultural perspective to migration (Fielding, 1992; Cohen \& Sirkeci, 2011), I identified migration as an intrinsic variable in the daily lives of Nigerian university graduates - as Carling and Akesson (2009) found for Cape Verdean migrants - that influences the mindsets and attitudes of migrants, former migrants, and non-migrants. Migration is seen by Nigerian university graduates as a path to greener pastures that is worth their effort. Access to migration thus becomes the overall aim of Nigerian university graduates, despite circumstances contradicting this choice, such as secure employment in Nigeria or narratives drawing a rather negative image of living abroad.

Synthesizing my findings from the analysis of the interviews and the web-survey, I have showed that there are both personal and structural constraints hindering 
the effective use of the knowledge base of highly skilled Nigerian migrants. Typical personal constraints are, for instance, inadequate information and preparedness before emigration. The most important structural constraints are the differing educational systems and lack of accreditation of foreign degrees in the countries of destination, as well as an absence of funding for master's degree programs in the country of origin.

In this chapter, I have argued that education functions alongside networks as a facilitator of migration because requirements for a student visa are easier to fulfill and universities abroad are more likely to accept migrants who have a university degree. Furthermore, I defined six types of highly skilled Nigerian migrants to conceptualize migration as a dynamic process with several possible trajectories over time and space. Migration is thus no longer a uni- or bidirectional process, but, in fact, a multidirectional and multidimensional one with several back-and-forth steps, both in terms of national border crossings and shifting between the six migrant types. Accordingly, outcomes cannot be declared as either positive or negative, but need to be evaluated in specific contexts. Jöns (2015) concludes in respect to brain circulation that it "captures physical and virtual, temporary and permanent movements; it accounts for the increasingly networked nature of talent migration; and it avoids a priori assumptions about causal relationships between the nature, duration, and effects of talent mobility" (p. 374). Migrants often develop transnational links that go beyond chatting or communicating with private contacts. The development of transnational ways of life furthers the circulation of knowledge, capital, and value flows. These circulations may influence a variety of outcomes that cannot be foreseen.

With the introduction of a West African model depicting the migration process from the migrants' perspective, I incorporated the findings of my interviews and my web-survey into a more abstract model that is supported by other case studies (e.g., Ammassari, 2004; Efionayi \& Piguet, 2011; Hunter, 2011; Sinatti, 2011; Tiemoko, 2004). It depicts the migration process, from the migrants' images of destination countries and articulated reasons, to the migration facilitators, the accomplishment of migration, the integration process, and the possible intention of returning. Hereby I take into account that migrants can take multiple trajectories. However, the model indicates that the aims of migration are likely to shift with time, from status and greener pastures to transnationalism, which promotes brain circulation (e.g., Ho, 2011; Jöns et al., 2015; Larner, 2007). Nigeria could, therefore, usefully draw on its highly skilled migrants abroad, as it is already attempting to do through, for instance, migrant diaspora organizations such as the Nigerians in Diaspora Organization (NIDO).

Educational migration can be regarded as harmful to Nigerian educational and economic systems, although it can create benefits when transnational links are established between Nigerian universities and abroad, and between local and international companies in ways similar to those discussed by Saxenian $(2005,2006)$ in regard to transnational networks constituted through brain circulation between the United States and India, China, and other Asian countries. Further research could focus on the conditions that enable the establishment of mutually beneficial transnational linkages of highly skilled migrants between source and destination countries 
(concentrating on African countries), in an approach carried out for other countries in Asia, Europe, and the United States (for the IT sector, see Saxenian, 2006; for schools and universities, see Waters, 2006; 2007; Jöns, 2009; Jöns et al., 2015).

\section{References}

Adepoju, A. (1985). Development programmes and population redistribution in Nigeria. In C. I. Clarke, M. Khogali, \& L. A. Kosinski. (Eds.), Population and Development Projects in Africa (194-205). Cambridge, UK: Cambridge University Press.

Adepoju, A. (1995). The politics of international migration in post-colonial Africa. In R. Cohen (Ed.), The Cambridge survey of world migration (pp. 166-171). Cambridge, UK: Cambridge University Press.

Ammassari, S. (2004). From nation-building to entrepreneurship: The impact of élite return migrants in Côte d'Ivoire and Ghana. Population, Space and Place, 10, 133-154. doi:10.1002/ psp. 319

Akesson, L., \& Baaz Eriksson, M. (Eds.). (2015). Africa's return migrants: New developers? London: Zed Books.

Binaisa, I. N. (2009). Ugandan migrants in Britain: Negotiating spaces of "home" and "belonging”. University of Sussex, Brighton.

Carling, J. (2002). Migration in the age of involuntary immobility: Theoretical reflections and Cape Verdean experiences. Journal of Ethnic and Migration Studies, 28, 5-42. doi:10.1080/13691830120103912

Carling, J. (2014). The role of aspirations in migration. Paper presented at a conference on "Determinants of International Migration" Oxford.

Carling, J., \& Akesson, L. (2009). Mobility at the heart of the nation: Patterns and meanings of Cape Verdean migration. International Migration, 47, 123-155. doi:10.1111/j.1468-2435.2009.00526.x

Carling, J., Fall, P. D., Hernandez-Carretero, M., Sarr, Y. M., \& Wu, J. (2013). Migration aspirations in Senegal: Who wants to leave and why does it matter? European Policy Brief. Brussels: European Commission.

Castells, M. (2000). The rise of the network society. Oxford: Blackwell.

Cebula, R. J. (1979). The determinants of human migration. Toronto: Lexington Books.

Chikanda, A. (2007). Medical migration from Zimbabwe: Magnitude, causes and impact on the poor. Development Southern Africa, 24, 47-60. doi: 10.1080/03768350601165850

Choldin, H. M. (1999). Kinship networks in the migration process. In S. Vertovec \& R. Cohen (Eds.), Migration, diasporas, and transnationalism (pp. 163-175). Cheltenham: Elgar Reference Collection.

Cohen, J. H., \& Sirkeci, I. (2011). Cultures of migration. Austin: University of Texas Press.

Dannecker, P. (2009). Rationalities and images underlying labor migration from Bangladesh to Malaysia. International Migration, 51, 40-60. doi:10.1111/j.1468-2435.2009.00547.x

DaVanzo, J. (1981). Microeconomic approaches to studying migration decision. In G. F. De Jong \& R. W. Gardner (Eds.), Migration decision making (pp. 90-129). New York: Pergamon Press.

Efionayi, D., \& Piguet, E. (2011). Partir ou rester? La migration dans le projet de vie des étudiants universitaires d'Afrique de l'ouest: Université de Neuchâtel, École Polytechnique Fédérale de Lausanne, Maison D'Analyse des Processus Sociaux, Swiss Forum for Migration and Population Studies. (Leave or stay? Migration aspirations in the project of accompanying university students in West Africa)

Faist, T. (2008). Migrants as transnational development agents: An inquiry into the newest round of the migration-development nexus. Population, Space and Place, 14, 21-42. doi:10.1002/ psp. 471

Falola, T. (1999). History of Nigeria. Westport: Greenwood Press. 
Fawcett, J. T. (1989). Networks, linkages, and migration systems. International Migration Review, 23, 671-680. doi:10.2307/2546434

Fielding, A. (1992). Migration and Culture. In T. Champion \& T. Fielding (Eds.), Migration processes and patterns: Vol. 1. Research progress and prospects (pp. 201-212). London: Belhaven Press.

Findlay, A. M. (1995). Skilled transients: The invisible phenomenon? In R. Cohen (Ed.), The Cambridge survey of world migration (pp. 515-522). Cambridge, UK: Cambridge University Press.

Fossland, T. (2013). Crossing borders - getting work: Skilled migrants' gendered labour market participation in Norway. Norsk Geografisk Tidsskrift - Norwegian Journal of Geography, 67, 276-283. doi: 10.1080/00291951.2013.847854

Gardner, R. W. (1981). Macrolevel influences on the migration decision process. In G. F. De Jong. \& R. W. Gardner (Eds.), Migration decision making (pp. 59-98). Oxford: Pergamon Press.

Goldin, I., Cameron, G., \& Balarajan, M. (Eds.). (2009). Exceptional people. How migration shaped our world and will define Our future. Princeton: Princeton University Press.

Goldring, L. (2001). Disaggregating transnational social spaces. In L. Pries (Ed.), New transnational social spaces (pp. 59-76). London: Routledge.

Hardwick, S. W. (2008). Place, space and pattern. In C. B. Brettel \& J. F. Hollifield (Eds.), Migration theory (2nd ed., pp. 161-182). London: Routledge.

Ho, E. L-E. (2011). "Claiming" the diaspora: Elite mobility sending state strategies and the spatialities of citizenship. Progress in Human Geography, 35, 757-772. doi:10.1177/0309132511401463

Hunter, A. (2011). Theory and practice of return migration at retirement: The case of migrant worker hostel residents in France. Population, Space and Place, 17, 179-192. doi:10.1002/ psp. 610

Jöns, H. (2015). Talent mobility and the shifting geographies of Latourian knowledge hubs. Population, Space and Place, 21, 372-389. doi:10.1002/psp.1878

Jöns, H. (2009). "Brain circulation" and transnational knowledge networks: studying long-term effects of academic mobility to Germany, 1954-2000. Global Networks, 9, 315-338. doi:10.1111/j.1471-0374.2009.00256.X

Jöns, H., Mavroudi, E., \& Heffernan, M. (2015). Mobilising the elective diaspora: US-German academic exchanges since 1945. Transactions of the Institute of British Geographers, 40, 113127. doi: $10.1111 / \operatorname{tran} .12062$

Kennedy, P., \& Roudometof, V. (Eds.). (2002). Communities across borders. London: Routledge.

King, R. (2012). Geography and migration studies: Retrospect and prospect. Population, Space and Place, 18, 134-153. doi:10.1002/psp.685

Larner, W. (2007). Expatriate experts and globalizing governmentalities: The New Zealand diaspora strategy. Transactions of the Institute of British Geographers, 32, 311-324. doi:10.1111/j.1475-5661.2007.00261.x

Larsen, J., Urry, J., \& Axhausen, K. (2006). Mobilities, networks, geographies. Farnham: Ashgate.

Lee, J. T., \& Kim, D. (2010). Brain gain or brain circulation? U.S. doctoral recipients returning to South Korea. Higher Education, 59, 627-643. doi: 10.1007/s10734-009-9270-5

Levitt, P. (1998). Social remittances: Migration driven local-level forms of cultural diffusion. International Migration Review, 32, 926-948. doi: 10.2307/2547666

Makinwa-Adebusoye, P. (1992). The West African migration system. In M. M. Kritz, L. L. Lim, \& H. Zlotnik (Eds.), International migration systems. Oxford: Clarendon Press.

Mitchell, K. (2000). Networks of ethnicity. In E. Sheppard \& T. J. Barnes (Eds.), A companion to economic geography (pp. 392-408). Oxford: Blackwell. doi: 10.1002/9780470693445.ch24

Nieswand, B. (2014). The burgers' paradox: Migration and the transnationalization of social inequality in southern Ghana. Ethnography, 15, 403-425. doi:10.1177/1466138113480575

Parnwell, M. (Ed.). (1993). Population movements and the third world. London: Routledge.

Pecoraro, M. (2013). Gender, brain waste and job-education mismatch among migrant workers in Switzerland. Working Paper Series of the Social Science Research Network (SSRN), 111.

Portes, A., \& DeWind, J. (2004). A cross-Atlantic dialogue: The progress of research and theory in the study of international migration. International Migration Review, 38, 828-851. doi:10.1111/j.1747-7379.2004.tb00221.x 
Ralph, D., \& Staeheli, L. A. (2011). Home and migration: Mobilities, belongings and identities. Geography Compass, 5, 517-530. doi: 10.1111/j.1749-8198.2011.00434.x

Rizzica, L. (2008). The impact of skilled migration on the sending country: Evidence from African medical brain drain. Rivista Di Politica Economia, 98, 195-231.

Salt, J., \& Findlay, A. (1989). International migration of highly-skilled manpower: Theoretical and developmental issues. In R. Appleyard (Ed.), The impact of international migration on developing countries (pp. 159-180). Paris: OECD.

Saxenian, AL. (2005). From brain drain to brain circulation: Transnational communities and regional upgrading in India and China. Studies of Comparative International Development, 40, $35-61$.

Saxenian, AL. (2006). The new argonauts: Regional advantage in a global economy. Cambridge, MA: Harvard University Press.

Sinatti, G. (2011). "Mobile transmigrants" or "unsettled returnees"? Myth of return and permanent resettlement among Senegalese migrants. Population, Space and Place, 17, 153-166. doi: $10.1002 /$ psp. 608

Smith, L. (2015). Aspirations to go: Understanding the bounded rationality of prospective migrants from Ghana. In M. van der Velde \& T. van Naerssen (Eds.), Mobility and migration choices: Thresholds to crossing borders (pp. 29-42). Farnham: Ashgate.

Swindell, K. (1995). People on the move in West Africa: From pre-colonial polities to post-independence states. In R. Cohen (Ed.), The Cambridge survey of world migration (pp. 196-202). Cambridge, UK: Cambridge University Press.

Tiemoko, R. (2004). Migration, return and socio-economic change in West Africa: The role of family. Population, Space and Place, 10, 155-174. doi:10.1002/psp.320

Tilly, C. (2007). Trust networks in transnational migration. Sociological Forum, 22, 3-24. doi:10.1111/j.1573-7861.2006.00002.x

Utas, M. (2012). Bigmanity and network governance in Africa. In M. Utas. (Ed.), African conflicts and informal power: Big men and networks (pp. 1-31). London: Zed.

van der Velde, M., \& van Naerssen, T. (2015). The thresholds to mobility disentangled. In M. van der Velde, \& T. van Naerssen (Eds.), Mobility and migration choices: Thresholds to crossing borders (pp. 3-14). Farnham: Ashgate.

Waters, J. L. (2007). "Roundabout routes and sanctuary schools": The role of situated educational practices and habitus in the creation of transnational professionals. Global Networks, 7, 477-497.

Waters, J. L. (2006). Emergent geographies of international education and social exclusion. Antipode, 38, 1046-1068. doi:10.1111/j.1467-8330.2006.00492.x

Wolpert, J. (1965). Behavioral aspects of the decision to migrate. Papers of the Regional Science Association, 15, 159-167. doi:10.1111/j.1435-5597.1965.tb01320.x

Xiang, B., \& Lindquist, J. (2014). Migration infrastructure. International Migration Review, 48, 122-148. doi:10.1111/imre.12141

Open Access This chapter is distributed under the terms of the Creative Commons Attribution 4.0 International License (http://creativecommons.org/licenses/by/4.0/), which permits use, duplication, adaptation, distribution and reproduction in any medium or format, as long as you give appropriate credit to the original author(s) and the source, provide a link to the Creative Commons license and indicate if changes were made.

The images or other third party material in this chapter are included in the work's Creative Commons license, unless indicated otherwise in the credit line; if such material is not included in the work's Creative Commons license and the respective action is not permitted by statutory regulation, users will need to obtain permission from the license holder to duplicate, adapt or reproduce the material.

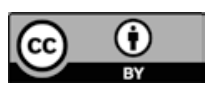

